\title{
MANCHESTER
}

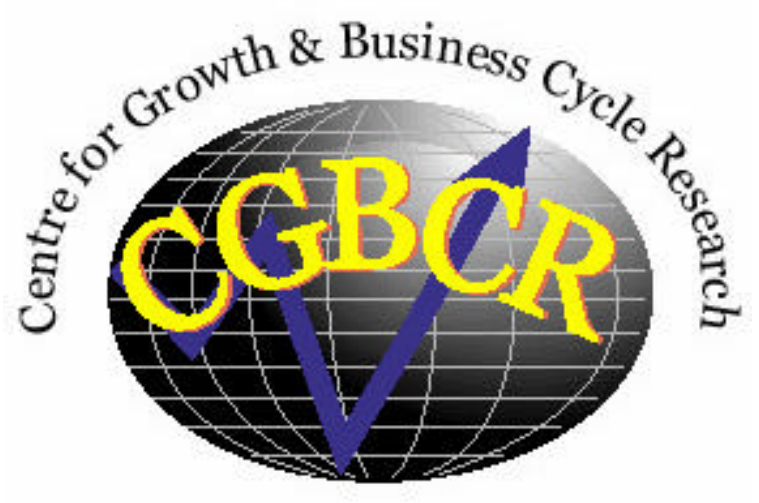

Discussion Paper Series

\section{Infrastructure, Public Education and Growth with Congestion Costs}

\author{
By \\ Pierre-Richard Agénor
}

Centre for Growth and Business Cycle Research, Economic Studies, University of Manchester, Manchester, M13 9PL, UK

January 2005

Number 047

Download paper from:

http://www.ses.man.ac.uk/cgbcr/discussi.htm 


\title{
Infrastructure, Public Education and Growth with Congestion Costs
}

\author{
Pierre-Richard Agénor* \\ Hallsworth Professor of International Macroeconomics \\ and Development Economics \\ Centre for Growth and Business Cycle Research \\ University of Manchester, United Kingdom \\ First complete draft: May 5, 2004 \\ This version: December 9, 2005
}

\begin{abstract}
This paper studies the optimal allocation of public expenditure between infrastructure and education services in an endogenous growth framework. Raw labor must be educated to become productive. The balanced-growth path is derived and the transitional dynamics associated with an increase in the share of spending on infrastructure are characterized. The growth-maximizing share is shown to depend on the elasticities of output with respect to both infrastructure services and the supply of educated labor. If the supply of raw labor is increasing in wages, the growth-maximizing share of government spending on infrastructure depends negatively on the degree of congestion in schooling.
\end{abstract}

JEL Classification Numbers: O41, H54, I28

*I am grateful to participants at seminars at the World Bank and the University of Manchester, as well as two anonymous referees, for comments on a previous draft. The views expressed here, however, are my own. 


\section{Contents}

1 Introduction 3

2 The Economy $\quad 7$

2.1 Production ..................... 8

2.2 Household Preferences . . . . . . . . . . . . . . . . 8

2.3 Human Capital Accumulation . . . . . . . . . . . . . . 10

2.4 Government . . . . . . . . . . . . . . . . . 11

3 The Balanced-Growth Equilibrium 12

4 Increase in the Share of Infrastructure $\quad 16$

4.1 Steady-State Effects . . . . . . . . . . . . . . . . 16

4.2 Transitional Dynamics . . . . . . . . . . . . . 18

5 The Growth-Maximizing Policy 19

6 Congestion Costs 23

7 Concluding Remarks $\quad 27$

$\begin{array}{ll}\text { References } & 30\end{array}$

Appendix A: Proportional Tax on Output 33

Appendix B: Independent Shares and Lump-sum Transfers 37

Figure 1: The Steady-Growth Equilibrium 42

Figure 2: Permanent Increase in the share of Public Spending on Infrastructure 43 


\section{Introduction}

Endogenous growth theories have stressed the importance of human capital accumulation as a determinant of growth in per capita income. In a seminal contribution, Lucas (1988) developed a model in which individual decisions to invest in education lead to an increase in the economy's stock of human capital and capacity to produce. The process driving human capital accumulation depends on its current stock and the fraction of non-leisure time that workers devote to training and learning, as opposed to current production. If the returns to education do not decline over time, private spending on education (or investment in human capital) becomes the main source of long-run growth.

A key feature of the Lucas model is that the decision to invest in education, and thus the path of human capital, depends on the individual's decision regarding how much training he or she is willing to undertake. Because everything else in the model depends on the path of human capital, the dynamic behavior of the economy and the steady-state growth rate are completely determined by the way individuals decide to allocate their time. However, as pointed out for instance by Creedy and Gemmell (2002), the hypothesis that education decisions are entirely private ignores the fact that in many developing countries education is provided free of charge, at least at the primary and secondary levels, by the government, and that school attendance is mandatory. Individuals can therefore choose the intensity (or level of effort) provided in acquiring education, but the amount of time that is allocated to studying is subject to a lower bound, fixed by government fiat. ${ }^{1}$ Moreover, in the presence of credit market imperfections and human capital externalities, private agents may have only weak incentives, and insufficient resources, to

\footnotetext{
${ }^{1}$ By itself, this does not invalidate the Lucas model; the fraction of time allocated to studying can be reinterpreted as the additional time that individuals allocate to homework. In the model of Fisher and Keuschnigg (2002), for instance, self-study (or homework) and school attendance are substitutable inputs (to some degree) in the acquisition of skills.
} 
finance their own education. In such conditions, publicly-provided education can reduce or eliminate the negative externalities that affect individual decisions to accumulate human capital.

Various contributions have extended the Lucas framework to account for government spending on education, as well as other services (such as health, infrastructure, or utility-enhancing services). They include $\mathrm{Ni}$ and Wang (1994), Glomm and Ravikumar (1992, 1998, 2003), Baier and Glomm (2001), van Zon and Nuysken (2001), Fisher and Keuschnigg (2002), Rioja and Glomm (2003), Rivas (2003), and Blankenau and Simpson (2004). Some of these contributions have explicitly studied the extent to which an increase in the public provision of education services raises long-run growth, by altering the process of human capital accumulation. For instance, in Glomm and Ravikumar (1992, 1998, 2003), the learning technology has two inputs: the time that each individual spends studying, and the quality of schools, which is a publicly-provided input common to all individuals. School quality depends on government expenditure, so labor productivity varies with increases in public spending. Blankenau and Simpson (2004) developed an overlappinggenerations model where human capital accumulation results from the provision of both public and private services, which are imperfect substitutes. Public services are proportional to output, whereas the per unit cost of private investment in human capital is proportional to the wage rate. They found that growth depends on the share of government spending on education in output, the ratio of physical capital to human capital, and per capita private investment in human capital. Both sets of studies, however, abstract from the provision of infrastructure and do not consider trade-offs that may arise in the allocation of public expenditure.

This paper departs from the existing literature in several ways. First, it abstracts entirely from private decisions to acquire skills and assumes instead that education is public and free of charge. The absence of an investment function in education for individuals is the consequence of education being 
mandatory. These assumptions are particularly relevant for low-income developing countries, where the scarcity of human capital have led states to pursue active policies to promote education, and private schooling opportunities are limited. Education, however, is not a pure public good: although it is non-excludable, I assume initially that it is rival as a result of a governmentimposed "admissions" policy that limits the number of individuals who are allowed in schools. Second, I account simultaneously for the provision of education and infrastructure services, in order to study potential trade-offs associated with the allocation of public spending. ${ }^{2}$ The growth effects of public spending on infrastructure have attracted much interest in recent years. In an early contribution by Barro (1990), public investment was treated as a flow; subsequent contributions by Turnovsky and Fisher (1995), Chang (1999), Fiaschi (1999), Turnovsky (2000), and Eicher and Turnovsky (2000), followed that approach as well. In the model developed in this paper, growth depends also on the flow of government spending on infrastructure, in addition to the provision of education services. As a result, the optimal allocation of tax revenue can be examined. The fact that all components of spending are productive, and that the government faces a budget constraint, makes this issue non trivial from a growth perspective - particularly for low-income countries, where needs are great in both education and infrastructure.

Third, the model assumes that the economy is endowed only with "raw" labor, and that raw labor must be educated to become productive. Knowledge is thus "embodied" in (educated) workers, unlike Lucas-type models where human capital is disembodied and can therefore grow without bounds. In the framework developed in this paper, the growth rate of educated labor is subject to an upper bound, the growth rate of the population itself

\footnotetext{
${ }^{2}$ Rivas (2003) for instance examined the impact of changes in the allocation of government spending (for given tax rates) between government consumption, transfer payments, and the provision of infrastructure services in an endogenous growth framework. He did not, however, account for human capital accumulation and publicly-provided education services, and did not derive optimal allocation rules.
} 
(which is kept exogenous). Fourth, the model accounts for congestion costs in education - an important feature of education systems in the developing world, particularly in low-income countries. According to World Bank estimates, in 1999, the pupil-teacher ratio in primary schooling (a common indicator of the quality of education) was 16.9 for high-income countries, but reached 21.4 in middle-income countries and 38.9 in low-income countries. In the same year, the ratio was 41.5 in South Asia and 46.7 in sub-Saharan Africa. Most recent estimates for those regions put the ratio at 40 and 44, respectively (see UNESCO (2005)). Overcrowded classrooms affect the benefits of public education, both in terms of quality and quantity. Infrastructurerelated congestion costs have been studied in several contributions in the endogenous growth literature, ${ }^{3}$ but congestion costs (or quality issues) associated with the provision of education services have not, as far as I know, been dealt with in detail. Glomm and Ravikumar (1992, 1998, 2003) relate the quality of schools to public spending on education (as noted earlier) but, given their assumption of a linear relationship between these two variables, they do not allow for congestion effects. They also abstract from infrastructure spending. The only contribution that I am aware of is a study by Tamura (2001). He allows for congestion effects by introducing a trade-off between teacher quality and class size in the production of human capital in determining school quality (that is, smaller classes provide better learning environments, but the detrimental effects of larger classes can be mitigated by improving the quality of teachers). He focuses, however, on convergence issues, rather than the optimal allocation of public resources as I do here. ${ }^{4}$

The remainder of the paper is organized as follows. Section II presents the basic framework. A key assumption underlying the model is that education

\footnotetext{
${ }^{3}$ See for instance Fisher and Turnovsky (1998), Glomm and Ravikumar (1999), and Eicher and Turnovsky (2000), where the use of public capital is congested by the use of private capital.

${ }^{4}$ Rioja and Glomm (2003) consider both public education and public provision of infrastructure services, as I do here. However, they do not provide an explicit analysis of the optimal allocation of public resources.
} 
is provided (free of charge) through a schooling technology that depends on the provision of government services. These services, as well as spending on infrastructure, are financed by a distortionary tax on installed capital. Section III derives the balanced-growth equilibrium and discusses the dynamic properties of the model. Section IV examines the short- and long-run effects of an increase in the share of government spending on infrastructure services. The analysis shows that there is a trade-off in increasing public spending on infrastructure: on the one hand, it leads to an increase in the productivity of private capital, which increases growth, but on the other, it leads to a reduction in the rate of human capital accumulation, which lowers growth. Thus, the long-run effect on steady-state growth is ambiguous; depending on the parameters that characterize the production technology, an increase in public spending on infrastructure can actually lower the growth rate. Section V derives the optimal (or growth-maximizing) allocation of public expenditure between education and infrastructure, and examines its sensitivity to various structural parameters. Section VI introduces congestion costs in public education. I do so by assuming that the efficiency of government-provided education services declines with the number of potential students (that is, the number of individuals in the raw labor force seeking to acquire skills). The last section of the paper summarizes the main results and discusses some possible extensions of the analysis.

\section{The Economy}

Consider an economy populated by a single infinitely-lived household who produces and consumes a single traded good, which can be used for consumption or investment. The economy's endowment consists of raw labor, which must be educated to be used in the production process. The government provides infrastructure and education services (with the former consisting of spending on transportation, communication, sewers, water systems, and so 
on, and the second consisting of expenditure on books, lunches, and so on) free of charge. It levies a flat tax on installed capital to finance its outlays. All individuals in the raw labor force (which grows at a constant rate) seek to acquire skills; however, not all of them have access to the education system. The number of students is set through an "admissions" policy, which involves (as discussed later) some form of rationing. As a result, whereas infrastructure services are a pure (that is, non-rival, non-excludable) public good, education is not; it is non-excludable (an uneducated individual cannot prevent other individuals from accessing the education services that the government provides at no cost), but it is rival (the use of the education system by a sufficient number of uneducated individuals precludes its use by others).

\subsection{Production}

Output, $Y$, is produced with private physical capital, public infrastructure services, and educated labor, using a Cobb-Douglas technology:

$$
Y=G^{\alpha} E^{\beta} K_{P}^{1-\alpha-\beta},
$$

where $K_{P}$ is the stock of private capital, $G$ government services, $E$ the stock of educated labor, and $\alpha, \beta \in(0,1)$. Thus, production exhibits constant returns to scale in all factors. Moreover, as long as $G / K_{P}$ and $E / K_{P}$ are constant, output is proportional to the private capital stock; the production function is then an $A K$-type technology, which implies that the equilibrium is characterized by steady-state growth. Indeed, as shown below, steady-state growth occurs even with decreasing returns to scale in reproducible factors of production (educated labor and private capital).

\section{$2.2 \quad$ Household Preferences}

Assuming no disutility associated with working, and no utility per se from the acquisition of skills, the infinitely-lived household maximizes the discounted 
stream of future utility ${ }^{5}$

$$
\max _{C} V=\int_{0}^{\infty} \ln C_{t} \exp (-\rho t) d t
$$

where $C$ is consumption and $\rho>0$ the discount rate. Consumption enters the instantaneous utility function in logarithmic form, implying that income and substitution effects cancel out, and that the household's propensity to save (and invest) is independent of the rate of return on capital. Moreover, unlike some contributions in the literature - such as Barro (1990), Turnovsky and Fisher (1995), Baier and Glomm (2001), Rioja and Glomm (2003), and Turnovsky (2004) - I do not allow for utility-enhancing public services. ${ }^{6}$

The household budget constraint is

$$
C+\dot{K}_{P}=Y-\tau K_{P}
$$

where $\tau \in(0,1)$ is the tax rate on capital. For simplicity, the depreciation rate of private capital is assumed to be zero.

Using (1) and (2), the current-value Hamiltonian for this problem can be written as

$$
H=\ln C+\lambda\left[G^{\alpha} E^{\beta} K_{P}^{1-\alpha-\beta}-\tau K_{P}-C\right],
$$

where $\lambda$ is the costate variable associated with constraint (2). From the firstorder condition $d H / d C=0$ and the costate condition $d H / d K_{P}=\rho \lambda-\dot{\lambda}$, optimality conditions for this problem can be written as:

$$
\begin{gathered}
1 / C=\lambda, \\
\dot{\lambda}=\lambda\left[\tau+\rho-(1-\alpha-\beta) G^{\alpha} E^{\beta} K_{P}^{-\alpha-\beta}\right],
\end{gathered}
$$

together with the budget constraint (2) and the transversality condition

$$
\lim _{t \rightarrow \infty} \lambda_{t} K_{P, t} \exp (-\rho t)=0 .
$$

\footnotetext{
${ }^{5}$ Throughout the paper, the time subscript $t$ is omitted whenever doing so does not result in confusion. A dot over a variable is used to denote its time derivative.

${ }^{6}$ For a more general specification of instantaneous utility in this class of models, see Agénor $(2005 a, 2005 d)$.
} 
Equations (3) and (4) can be combined to give

$$
\frac{\dot{C}}{C}=-\frac{\dot{\lambda}}{\lambda}=(1-\alpha-\beta)\left(\frac{G}{K_{P}}\right)^{\alpha}\left(\frac{E}{K_{P}}\right)^{\beta}-\tau-\rho .
$$

\subsection{Human Capital Accumulation}

As noted earlier, raw labor must be educated to become productive. The schooling technology is specified as a two-level production function. At the first level, the prevailing quantity of educated labor, $E$, and government spending on education, $I_{E}$, are combined to produce a composite input. At the second level, this input is combined with the number of individuals seeking to acquire an education, $L$, to produce the flow of newly-educated workers, $N$. Thus, a more literate environment leads to the production of a greater number of educated workers, for given levels of public spending on education and individuals seeking to acquire skills. ${ }^{7}$

Assuming that technology is Cobb-Douglas at both levels yields:

$$
N=A\left(I_{E}^{\omega} E^{1-\omega}\right)^{\eta} L^{1-\eta},
$$

where $A$ is a scale parameter and $\omega, \eta \in(0,1)$. The schooling technology exhibits therefore constant returns to scale in $E$ and $I_{E}$ (taken separately), as well as in the composite input $I_{E}^{\omega} E^{1-\omega}$ and $L$.

Equation (7) can be rewritten as

$$
N=A\left(\frac{I_{E}^{\omega} E^{1-\omega}}{L}\right)^{\eta} L=A\left(\frac{I_{E}}{E}\right)^{\omega \eta}\left(\frac{E}{L}\right)^{\eta} L .
$$

As shown later, in the steady state the growth rate of educated labor, $N / E$ is positive. However, given the schooling technology (7), $E$ cannot grow without bound; it cannot, in fact, exceed the growth rate of the stock

\footnotetext{
${ }^{7}$ Note that it could have been assumed (as in Agénor $(2005 a, 2005 b)$ ) that a fraction $\chi$ of the total stock of educated labor consists of teachers on the government's payroll, with the rest engaged in the production of goods. However, this would only change the definitions of the constant terms in (1) and (7) and would not affect the results in any way, as long as $\chi$ is constant.
} 
of raw labor admitted in schools, $n .^{8}$ Thus, $N / E \leq n$. In order to abstract from considerations related to endogenous population growth, I impose this restriction in a particularly simple way - I assume a strictly proportional relation between $E$ and $L$, of the form $L=\varphi E$, where $\varphi>0$. Thus, in the steady state, $L$ grows at the same rate as $E$, implying that the ratio $L / E$ is constant. In effect, this restriction amounts to assuming that the government rations access to public education by fixing $n$. The case where $L$ responds endogenously to changes in wages is examined later. ${ }^{9}$

Substituting $L=\varphi E$ in (8) implies that the growth rate of $E$ evolves over time according to

$$
\frac{\dot{E}}{E}=\frac{N}{E}-\delta_{E}=B\left(\frac{I_{E}}{E}\right)^{\omega \eta}-\delta_{E}
$$

where $B=A \varphi^{1-\eta}$, and $\delta_{E} \in(0,1)$ denotes the rate of "depreciation" (or de-skilling) of educated labor. Note also that I have not accounted for the possibility that public infrastructure may affect the schooling technology and therefore the ability to produce educated labor; this issue is discussed at length elsewhere (see Agénor (2005a, 2005b)).

\subsection{Government}

The government provides infrastructure and education services, $G$ and $I_{E}$. As in Park and Philippopoulos (2004), for instance, it collects a proportional tax on private installed capital at the rate $\tau \in(0,1) .{ }^{10}$ Thus, the government

\footnotetext{
${ }^{8}$ Note that $n$ is endogenous, whereas the growth rate of the overall raw labor force itself is exogenous and must in turn exceed (or be equal to) $n$.

${ }^{9}$ Note also that if it had been assumed (as indicated earlier) that a fraction of the stock of educated labor consists of public sector teachers, the interpretation of this restriction would be straightforward: it would mean that the government is trying to achieve a constant pupils-to-teachers ratio by limiting the number of individuals accepted in the classrooms. The results would be, nevertheless, qualitatively similar to those discussed later, so the simpler specification in (7) is used.

${ }^{10}$ The assumption that the tax is proportional to installed capital is made for simplicity only. As shown in Appendix A, the results are qualitatively same if instead a proportional
} 
budget constraint is given by

$$
I_{E}+G=\tau K_{P}
$$

Assuming that infrastructure services are a constant fraction of tax revenue, so that $G=v \tau K_{P}$, with $v \in(0,1)$, the government budget constraint can be rewritten as

$$
I_{E}=(1-v) \tau K_{P},
$$

which determines the share of spending on education services, $1-v$. Thus, because $G / I_{E}=v /(1-v)$, the composition of public spending is constant over time, as long as $v$ is constant.

\section{The Balanced-Growth Equilibrium}

The balanced-growth equilibrium (BGE) can be determined as follows. First, Equation (2) can be rewritten as, using (1),

$$
\dot{K}_{P}=\left(\frac{G}{K_{P}}\right)^{\alpha}\left(\frac{E}{K_{P}}\right)^{\beta} K_{P}-\tau K_{P}-C,
$$

that is, using $G / K_{P}=\tau v$,

$$
\frac{\dot{K}_{P}}{K_{P}}=(\tau v)^{\alpha} e^{\beta}-\tau-c,
$$

where $c=C / K_{P}$ and $e=E / K_{P}$.

Similarly, Equation (6) can be rewritten as

$$
\frac{\dot{C}}{C}=(1-\alpha-\beta)(\tau v)^{\alpha} e^{\beta}-\tau-\rho,
$$

whereas equation (9) gives

$$
\frac{\dot{E}}{E}=B\left[\left(\frac{I_{E}}{K_{P}}\right)\left(\frac{K_{P}}{E}\right)\right]^{\omega \eta}-\delta_{E}
$$

tax on output is assumed. Note also that, unlike the assumption in Park and Philippopoulos (2004), the tax is here taken to be paid out of current income. 
Consequently, given that from (11) $I_{E} / K_{P}=\tau(1-v)$,

$$
\frac{\dot{E}}{E}=B[\tau(1-v)]^{\omega \eta} e^{-\omega \eta}-\delta_{E} .
$$

Combining equations (12), (13), and (15) yields

$$
\begin{gathered}
\frac{\dot{c}}{c}=-(\alpha+\beta)(\tau v)^{\alpha} e^{\beta}-\rho+c, \\
\frac{\dot{e}}{e}=B[\tau(1-v)]^{\omega \eta} e^{-\omega \eta}-\delta_{E}-(\tau v)^{\alpha} e^{\beta}+\tau+c .
\end{gathered}
$$

These two nonlinear differential equations in $c$ and $e$, together with the initial condition $e_{0}=E_{0} / K_{P, 0}>0$ and the transversality condition (5), rewritten as

$$
\lim _{t \rightarrow \infty} c_{t}^{-1} \exp (-\rho t)=0,
$$

characterize the dynamic equilibrium. The BGE is a set of functions $\left\{c_{t}, e_{t}\right\}_{t=0}^{\infty}$ such that equations (16) and (17) and the transversality condition (18) are satisfied, and consumption, the stock of educated labor, and the stock of private capital, all grow at the same constant rate $\gamma$, that is, $\dot{C} / C=\dot{E} / E=$ $\dot{K}_{P} / K_{P}=\gamma \cdot{ }^{11}$ This is also the rate of growth of output. ${ }^{12}$ From (16), setting $\dot{c}=0$ yields

$$
\tilde{c}=\rho+(\alpha+\beta)(\tau v)^{\alpha} \tilde{e}^{\beta},
$$

where $\tilde{e}$ and $\tilde{c}$ denote the stationary values of $e$ and $c$. This expression can be substituted in (17) with $\dot{e}=0$ to yield an implicit function of the form

$$
Q(\tilde{e} ; v)=0 .
$$

\footnotetext{
${ }^{11}$ The transversality condition (18) is satisfied along any interior BGE because consumption and the stock of private capital grow at the same constant rate, implying that the ratio $c=C / K_{P}$ is also constant.

${ }^{12}$ From (1), and given that $\dot{E} / E=\dot{K}_{P} / K_{P}$ on the BGE, $\dot{Y} / Y=\alpha \dot{G} / G+[\beta+(1-\alpha-$ $\beta)] \dot{K}_{P} / K_{P}$. Given that $G=v \tau K_{P}$, and thus $\dot{G}=v \tau \dot{K}_{P}$, this expression boils down to $\dot{Y} / Y=\dot{K}_{P} / K_{P}$.
} 
From (13), $\gamma$ is given by

$$
\gamma=(1-\alpha-\beta)(\tau v)^{\alpha} \tilde{e}^{\beta}-\tau-\rho,
$$

which shows that the growth rate depends on the production technologies for goods and educated labor (the latter through $\tilde{e}$ ), as well as fiscal policy variables $(\tau$ and $v)$. From (12) and (15), the growth rate is given by the equivalent forms

$$
\gamma=(\tau v)^{\alpha} \tilde{e}^{\beta}-\tau-\tilde{c}
$$

which is identical to (21) given (19), and

$$
\gamma=B[(1-v) \tau]^{\omega \eta} \tilde{e}^{-\omega \eta}-\delta_{E}
$$

To investigate the dynamics in the vicinity of the steady state, the system (16)-(17) can be linearized to give

$$
\left[\begin{array}{c}
\dot{c} \\
\dot{e}
\end{array}\right]=\left[\begin{array}{ll}
a_{11} & a_{12} \\
a_{21} & a_{22}
\end{array}\right]\left[\begin{array}{l}
c-\tilde{c} \\
e-\tilde{e}
\end{array}\right]
$$

where the $a_{i j}$ are given by

$$
\begin{gathered}
a_{11}=\tilde{c}, \quad a_{21}=\tilde{e}, \\
a_{22}=-\omega \eta B[\tau(1-v)]^{\omega \eta} \tilde{e}^{-\omega \eta}-\beta(\tau v)^{\alpha} \tilde{e}^{\beta}<0, \\
a_{12}=-\tilde{c} \beta(\alpha+\beta)(\tau v)^{\alpha} \tilde{e}^{\beta-1}<0 .
\end{gathered}
$$

$c$ is a jump variable, whereas $e$ is predetermined at any given moment in time. Saddlepath stability requires one unstable (positive) root. To ensure that this condition holds, the determinant of the Jacobian matrix of partial derivatives of the dynamic system (24) must be negative, that is, $\Delta=a_{11} a_{22}-$ $a_{12} a_{21}<0$. Using the above definitions yields

$$
\Delta=-\tilde{c} \omega \eta A[\tau(1-v)]^{\omega \eta} \tilde{e}^{-\omega \eta}-\tilde{c} \beta(1-\alpha-\beta)(\tau v)^{\alpha} \tilde{e}^{\beta}<0 .
$$

This condition always holds, given that $\alpha+\beta<1$. Thus, in the neighborhood of the BGE, the dynamic system is saddlepath stable. There is a 
unique value of the initial level of consumption, $C_{0}$, which can be chosen freely by the household, such that the economy converges to the BGE in the long run. Moreover, under the restriction $\rho>\delta_{E}-\tau$ (a condition that always holds if $\delta_{E} \rightarrow 0$ ), this equilibrium is unique. ${ }^{13}$ The model is thus locally determinate. ${ }^{14}$

The phase diagram in Figure 1 shows how the BGE equilibrium is reached. The phase curve $C C$ represents the combinations of $c$ and $e$ for which the consumption-capital stock ratio is constant $(\dot{c}=0)$, whereas the phase curve $E E$ represents the combinations of $c$ and $e$ for which the educated laborcapital stock ratio is constant $(\dot{e}=0) .{ }^{15}$ Both curves have a concave shape, but saddlepath stability requires that the slope of $E E$ be steeper than the slope of $C C$ at the point at which they intersect, point $A$, which corresponds to the BGE.

From the linearization given above, the stable manifold is given by

$$
\begin{gathered}
e=\tilde{e}+\left(e_{0}-\tilde{e}\right) \exp (\nu t), \\
c=\tilde{c}+\kappa(e-\tilde{e}),
\end{gathered}
$$

where

$$
\kappa \equiv \frac{\nu-a_{22}}{\tilde{e}}=-\frac{a_{12}}{\tilde{c}-\nu}>0,
$$

is the slope of the saddlepath, denoted $S S$ in Figure 1, and $\nu$ denotes the

\footnotetext{
${ }^{13}$ To show that the BGE is unique, note first that from $(20) Q_{\tilde{e}}<0$. Thus, $Q(\tilde{e} ; v)$ cannot cross the horizontal axis from below. Suppose also that $\rho>\delta_{E}-\tau$, a condition that ensures that $Q(0 ; v)>0$. Given that $Q(\tilde{e} ; v)$ is a continuous, monotonically decreasing function of $\tilde{e}$, there is a unique positive value of $\tilde{e}$ that satisfies $Q(\tilde{e} ; v)=0$. From (19), there is also a unique positive value of $\tilde{c}$. Finally, note that, from (23), if $\delta_{E} \rightarrow 0, \gamma$ is always positive if $\tilde{e}>0$.

${ }^{14}$ Of course, the fact that the model is locally determinate in the neighborhood of the steady state does not imply that it is also globally determinate. In addition, multiple balanced growth paths can arise if the services derived from public spending on education are subject to, say, threshold effects. However, these issues are not pursued here.

${ }^{15}$ Inspection of (16) and (17) shows that the intercept of $C C$ is $\rho$, whereas, in general, the only thing that can be said about the intercept of $E E$ is that it is strictly positive. In the particular case where $\delta_{E}-\tau=0$, the intercept is $\left\{(\tau v)^{\alpha} / B[\tau(1-v)]^{\omega \eta}\right\}^{1 /(\beta+\omega \eta)}$.
} 
negative root of (24). ${ }^{16}$ During the transition, both ratios move in the same direction. The reason is that the transitional dynamics are driven by the ratio of educated labor to private capital $\left(G / K_{P}\right.$ is constant over time and equal to $\tau v$ ). For instance, as this ratio increases (starting from a point located on $S S$ to the left of $A$ ), the productivity of private capital increases as well. Although intertemporal substitution and income effects associated with the increase in the rate of return on capital exactly offset each other in the present case (given the assumption of a logarithmic instantaneous utility function), the increase in the level of output raises consumption by more than it increases the stock of private capital, and this tends to raise the consumption-capital ratio during the transition to point $A$.

\section{Increase in the Share of Infrastructure}

I now examine the response of the economy to an unanticipated, permanent increase in the share of spending on infrastructure, $v$, for a constant tax rate on capital, $\tau$. Clearly, given the balanced-budget assumption (see (10), at any given level of $K_{P}$ an increase in $v$ leads to a concomitant reduction in the share of spending on education services. Because both types of services affect production (directly, in the case of infrastructure, indirectly, in the case of education), it is intuitively clear that this policy will entail a trade-off with respect to its impact on the economy's growth rate and level of consumption.

\subsection{Steady-State Effects}

To determine the steady-state effects of an increase in $v$, note first that, from (20), and using the implicit function theorem, $\partial \tilde{e} / \partial v<0$. An increase in the share of spending on infrastructure services leads to a lower ratio of educated

\footnotetext{
${ }^{16}$ To show that $\kappa$ is positive, note that $\tilde{c}-\nu>0$ whereas $a_{12}<0$. To show that $S S$ is flatter than $C C$, note that $\kappa<-a_{12} / \tilde{c}$, because $a_{12} \nu>0$.
} 
labor to physical capital in the long run. From (19),

$$
\frac{d \tilde{c}}{d v}=(\alpha+\beta)(\tau v)^{\alpha} \tilde{e}^{\beta}\left[\alpha v^{-1}+\beta \tilde{e}^{-1}\left(\frac{d \tilde{e}}{d v}\right)\right],
$$

which is in general ambiguous in sign. $\partial \tilde{c} / \partial v$ is positive if, and only if

$$
\varepsilon_{\tilde{e} / v} \equiv-\left(\frac{d \tilde{e}}{d v}\right)\left(\frac{v}{\tilde{e}}\right)<\frac{\alpha}{\beta} .
$$

An increase in the share of spending on infrastructure leads to a higher consumption-capital ratio in the steady state only if the negative effect on the educated labor-capital ratio is not too large, given the relative impact of infrastructure services and educated labor on output. The reason is simply the linear dependence of steady-state consumption on the steady-state output-capital ratio, $(\tau v)^{\alpha} \tilde{e}^{\beta}$, as indicated in (19). The lower the elasticity of output with respect to educated labor is (the lower $\beta$ is), or the higher the elasticity of output with respect to infrastructure services, the higher the ratio $\alpha / \beta$ will be, and thus the more likely it is that output, and thus consumption (both measured in proportion of the private stock of capital) will increase in the long run.

From (21), the effect of an increase in the share of public investment on the steady-state growth rate is given by

$$
\frac{d \gamma}{d v}=(1-\alpha-\beta)(\tau v)^{\alpha} \tilde{e}^{\beta}\left[\alpha v^{-1}+\beta \tilde{e}^{-1}\left(\frac{d \tilde{e}}{d v}\right)\right],
$$

that is,

$$
\operatorname{sg}\left(\frac{d \gamma}{d v}\right)=\operatorname{sg}\left(\frac{d \tilde{c}}{d v}\right)=-\operatorname{sg}\left(\varepsilon_{\tilde{e} / v}-\frac{\alpha}{\beta}\right) .
$$

This result indicates that whether an increase in the share of government resources spent on infrastructure raises the economy's steady-state growth rate $(d \gamma / d v>0)$ depends on the same condition that determines whether the consumption-capital ratio rises. ${ }^{17}$

\footnotetext{
${ }^{17}$ This result obtains here because of the assumption of a logarithmic utility function. With a more general specification for instantaneous utility, it would not necessarily hold. In particular, the degree of intertemporal elasticity of substitution would matter (see Agénor (2005a)).
} 
The intuition behind the above results is straightforward. Increasing the fraction of government resources allocated to infrastructure has a direct, positive effect on private production (through the increase in $G / K_{P}$ on the marginal productivity of private capital), consumption, and long-run growth. At the same time, this increase reduces the provision of education services and lowers the supply of educated labor, which tends to lower private production, consumption, and the growth rate. For a given tax rate, there is therefore a trade-off between spending on education and infrastructure. If $\beta \rightarrow 0$, then $\gamma \rightarrow(1-\alpha)(\tau v)^{\alpha}-\tau-\rho$, and $d \gamma / d v \rightarrow \alpha(1-\alpha)(\tau v)^{\alpha-1}>0$. Put differently, if educated labor makes a small contribution to private production, an increase in $v$ has an unambiguously positive effect. Similarly, if $\alpha \rightarrow 0$, then $\gamma \rightarrow$ $(1-\beta) \tilde{e}^{\beta}-\tau-\rho$, and $d \gamma / d v \rightarrow \beta(1-\beta)(d \tilde{e} / d v)<0$ : if infrastructure services have a limited impact on private production, an increase in the share of resources allocated to the provision of these services will unambiguously reduce the economy's steady-state growth rate.

\subsection{Transitional Dynamics}

From (26), the impact effect of a rise in $v$ on the consumption-private capital ratio, given that $e$ cannot change instantaneously (so that $d e_{0} / d v=0$ ), is

$$
\frac{d c_{0}}{d v}=\frac{d \tilde{c}}{d v}-\kappa\left(\frac{d \tilde{e}}{d v}\right)
$$

which is also ambiguous, given that $\partial \tilde{c} / \partial v$ is ambiguous. Nevertheless, given that $\partial \tilde{e} / \partial v<0$, and $\kappa>0$, it can be established that ${ }^{18}$

$$
\operatorname{sg}\left(\frac{d c_{0}}{d v}\right)=\operatorname{sg}\left(\frac{d \tilde{c}}{d v}\right)
$$

The transitional dynamics associated with an increase in $v$ (assumed to be unanticipated at $t=0$ ) are illustrated in Figure 2, for "low" and "high" values

\footnotetext{
${ }^{18}$ Because the second term in (30) is positive, $\partial \tilde{c} / \partial v>0$ implies that $\partial c_{0} / \partial v$ is also positive. If $\partial \tilde{c} / \partial v<0$, given that the new saddlepath has a negative slope and shifts downward (see Figure 2), then $\partial c_{0} / \partial v$ must also be negative.
} 
of $\alpha / \beta$, as implied by (28). A rise in $v$ leads to a leftward shift in both $C C$ and $E E$. In the upper panel of the figure, $\alpha / \beta>\varepsilon_{\tilde{e} / v}$, and the consumptioncapital ratio jumps up on impact from $A$ to $B$, located on the new saddlepath $S^{\prime} S^{\prime}$. This leads to a reduction in the ratio of educated labor to private capital $\left(\dot{e}_{0}<0\right)$. Over time, both $c$ and $e$ fall along $S^{\prime} S^{\prime}$. In the lower panel of the figure, $\alpha / \beta<\varepsilon_{\tilde{e} / v}$, and the consumption-capital ratio jumps downward on impact from $A$ to $B$, and continues to decline (together with $e$ ) along $S^{\prime} S^{\prime}$ during the transition. In both cases, the economy converges monotonically to the new BGE, located at point $A^{\prime}$.

\section{The Growth-Maximizing Policy}

The foregoing discussion indicated that, as long as $\alpha / \beta$ is sufficiently large, an increase in $v$ will lead to an increase in private investment, a rise in the consumption-capital ratio, and a higher growth rate in the long run. This is because of the positive effect of higher infrastructure services on the marginal productivity of private capital, which offsets the adverse effect of the lower stock of educated labor. As $v$ is raised beyond a certain point, however, the positive marginal effect starts to decline (due to decreasing returns to each input), and the negative effect starts to increase. There is therefore a humpshaped curve linking the growth rate and $v$, and thus a growth-maximizing value for $v$, similar to that obtained by Barro (1990) in a setting in which the tax rate on output and the share of spending on infrastructure are one and the same. ${ }^{19}$

The growth-maximizing share of investment in infrastructure, $v^{*}$, is obtained by solving the condition $d \gamma / d v=0$ for $v$. From (29), this implies that

\footnotetext{
${ }^{19}$ See Tsoukis and Miller (2003), and Zagler and Durnecker (2003) for a review of Barro's results and its extensions. In Barro's (1990) model, with output taxes, the growth rate declines after a point with increases in the tax rate, as the adverse impact of distorting taxes (on private savings and investment) dominates the positive effect of public spending on the marginal productivity of capital. See Appendices A and B for a derivation of the optimal tax rate in the present setting and Agénor $(2005 d)$ for a more detailed discussion.
} 
$\beta v(d \tilde{e} / d v)+\alpha \tilde{e}=0$, that is, from (28),

$$
\varepsilon_{\tilde{e} / v}=\frac{\alpha}{\beta} .
$$

Thus, the optimal share $v^{*}$ corresponds to the value of $v$ for which the elasticity of the steady-state ratio of educated labor to private capital is equal to $\alpha / \beta$. Any increase in the share of public infrastructure beyond that point would reduce public investment in education and the steady-state ratio of educated labor to private capital, and thus indeed lower the growth rate, despite the positive effect of infrastructure services on the marginal productivity of private capital. In the present setting, the growth-maximizing policy is also the policy that maximizes the steady-state consumption-private capital ratio $(d \tilde{c} / d v=0)$.

An explicit interior solution for $v^{*}$ can be derived as follows. From the equivalent form for $\gamma$ given in (23), it can be shown that $d \gamma / d v=0$ implies that $v^{*} /\left(1-v^{*}\right)=\varepsilon_{\tilde{e} / v}$. Combining this result with (31) yields $v^{*} /\left(1-v^{*}\right)=$ $\alpha / \beta$, which can be rewritten as

$$
v^{*}=\frac{\alpha}{\alpha+\beta}
$$

Thus, an increase in $\alpha$ raises $v^{*}$, whereas an increase in $\beta$ lowers $v^{*}$. If $\beta=0$, so that educated labor has no effect on private production, the optimal share of spending on infrastructure is unity. Conversely, if $\alpha=0$ (that is, spending on infrastructure services has no effect on private output), then $v^{*}=$ 0. Put differently, the optimal share is positive as long as there are positive production externalities associated with public spending on infrastructure services. Note also that the optimal share $v^{*}$ is independent of the tax rate, as could be expected, but also of the education technology, as captured by the parameters $\omega$ and $\eta \cdot{ }^{20}$ As shown in Appendix A, the exact same results

\footnotetext{
${ }^{20}$ The latter result depends on the absence of congestion costs (as shown below), in addition to the assumption that the production and education technologies are CobbDouglas.
} 
obtain if government spending is financed by a proportional tax on output, as opposed to a tax on installed capital.

In terms of proportion of spending in output, formula (32) yields

$$
\frac{G^{*}}{Y}=\frac{\alpha}{\alpha+\beta}\left(\frac{\tau K_{P}}{Y}\right)
$$

which implies that (because output grows at the same rate as the capital stock), that $G^{*}$ is also growing at the rate $\gamma$, or equivalently that the ratio $G^{*} / Y$ is constant over time. This result also shows that the share of output spent on infrastructure services is linearly related to the tax rate; if $\beta=0$, this expression becomes $G^{*} / Y=\tau K_{P} / Y$, which indeed implies that all revenues should be spent on infrastructure. In an overlapping-generations model with no steady-state growth, a constant population, and no accumulation of human capital, Heijdra and Meijdram (2002, p. 727) found that the consumption-maximizing share of government spending on infrastructure, measured in proportion of output, is equivalent (in my notation) to $G^{*} / Y=\alpha$. This is exactly what Barro's (1990) analysis would predict. Turnovsky and Fisher (1995, p. 771) obtain a similar result in the context of a representative-household model with otherwise similar features. Intuitively, this rule amounts to setting the marginal physical product of infrastructure services to its resource cost of unity, that is, $d Y / d G=\alpha /\left(G^{*} / Y\right)=1 .^{21}$ The above formula can be seen as generalizing these results to the case where educated labor (or human capital) is also a reproducible factor and the economy experiences positive steady-state growth, given that in the present framework maximizing the growth rate or consumption of the household are equivalent. In the present case, given that $I_{E}^{*} / Y=[\beta /(\alpha+\beta)]\left(\tau K_{P} / Y\right)$, using (33),

$$
\begin{gathered}
\frac{d Y}{d G}=(\alpha+\beta)\left(\frac{\tau K_{P}}{Y}\right)^{-1}, \\
\frac{d Y}{d E}=\beta\left(\frac{Y}{E}\right)=(\alpha+\beta)\left(\frac{I_{E}}{E}\right)\left(\frac{\tau K_{P}}{Y}\right)^{-1} .
\end{gathered}
$$

\footnotetext{
${ }^{21}$ Put differently, in the Heijdra-Meijdram model, given that $\partial Y / \partial G=\alpha\left(Y / G^{*}\right)=$ $\alpha /\left(G^{*} / Y\right)$, then $G^{*} / Y=\alpha$ is equivalent to $\partial Y / \partial G=1$.
} 
The form of these expressions depends on the fact that the tax is levied on installed capital and that it is the stock of educated labor that enters in the production function, not spending on education services per se. If the tax is levied on output, and educated capital depreciates fully and instantaneously (so that $I_{E}=E$ ), the above results yield $d Y / d G=d Y / d I_{E}$ : the optimal allocation rule requires setting spending shares so that the marginal physical product of each component is the same.

Government resources could also be used for lump-sum transfers and for services that may provide direct utility to households, as in Barro (1990), Turnovsky and Fisher (1995), Baier and Glomm (2001), or Turnovsky (2004). For instance, if utility-enhancing services were also provided by the government, the equality between the growth-maximizing and consumptionmaximizing shares would not hold. Alternatively, intuition would suggest that the trade-off identified earlier regarding the impact of $v$ on the growth rate would be significantly less acute if the increase in spending on infrastructure comes at the expense of a reduction not in education services, but rather lump-sum transfers. As shown in Appendix B, this is not correct with a balanced-budget rule. If spending on both infrastructure and education services are fixed as a fraction of total resources, and transfers are determined as a residual to balance the budget and rebated in lump-sum fashion to the household, the "transfer rate" essentially acts as a reduction in the "effective" tax rate on private capital. Consequently, a rise in the share of spending on infrastructure would occur at the expense of transfers and would increase the effective tax rate, thereby reducing the rate of physical capital accumulation. If this effect is large, a rise in $v$ could be counter-productive, in the sense that it would lower the steady-state growth rate. ${ }^{22}$ In general, both $\tilde{e}$ and

\footnotetext{
${ }^{22}$ In an open economy, this adverse effect would disappear if the rise in $v$ is accompanied not by an offsetting change in other components of public expenditure but is instead financed by an increase in foreign aid (that is, a "pure" transfer from abroad, a very relevant scenario for low-income countries). An increase in $v$ would then unambiguously increase the long-run growth rate.
} 
$\tilde{c}$ respond ambiguously to an increase in $v$ (whereas in the previous case $\tilde{e}$ fell).

In general, as shown in Appendix B, explicit expressions for the optimal spending shares in infrastructure, $v^{*}$, and education services, $v_{E}^{*}$, are rather complicated when these shares are chosen independently of each other, and an interior solution is not guaranteed. ${ }^{23}$ However, if both rates are chosen simultaneously, it can be established that the ratio of optimal shares, $v^{*} / v_{E}^{*}$, is given by

$$
\frac{v^{*}}{v_{E}^{*}}=\frac{\alpha}{\beta},
$$

which is simply formula (32) if $v_{E}^{*}=1-v^{*}$ is imposed (see Appendix B).

\section{Congestion Costs}

To introduce congestion costs in the present setting, I assume that government spending on education, $I_{E}$, is less productive the higher the number of individuals in the raw labor force seeking to acquire skills. For instance, if $I_{E}$ represents spending on books used in the classroom, a greater number of students means that books must be shared, thereby making learning more laborious. Equation (7) is then replaced by

$$
N=A\left[\left(\frac{I_{E}}{L^{\phi}}\right)^{\omega} E^{1-\omega}\right]^{\eta} L^{1-\eta}=A\left(\frac{I_{E}}{E}\right)^{\omega \eta} E^{\eta} L^{1-\eta-\phi \omega \eta},
$$

where $\phi \in(0,1)$ measures the degree of congestion. Thus, an increase in the economy's stock of raw labor seeking an education reduces the efficiency of the education system and lowers the flow supply of educated labor if $1-\eta-\phi \omega \eta<0$, that is, $\phi>(1-\eta) / \omega \eta$. If $\phi=1$, then it is the provision of education services per school attendant, $I_{E} / L$, which determines the quantity of educated labor produced at any moment in time, as in Beauchemin (2001,

\footnotetext{
${ }^{23}$ One result that comes out clearly is that if the solution is feasible, both shares are positively related to the elasticity of output to private capital, $1-\alpha-\beta$.
} 
p. 294) for instance. In the logic of Tamura (2001), $I_{E} / L$ can then also be interpreted as an indicator of the quality of schooling.

To focus attention on the issue at hand (the impact of congestion costs on the optimal allocation rule), and to simplify algebraic results, I assume that $\eta=1$, so that raw labor is not used directly in the production of educated labor, and that $\delta_{E}=0$, so that $\dot{E}=N$. Thus, equation (35) yields

$$
\frac{\dot{E}}{E}=A\left(\frac{I_{E}}{E}\right)^{\omega} L^{-\theta}
$$

where $\theta=\phi \omega$. Thus, an increase in $L$ unambiguously lowers the growth rate of the stock of educated labor.

Note that the above specification is equivalent to one where congestion is taken to affect the overall efficiency of the education system, if efficiency is measured by $A L^{-\theta}$, or one in which it is the ratio of educated labor to raw labor (as a proxy for the teacher-student ratio, or the quality of teaching) that matters; in the latter case, equation (35), with $\eta=1$, would be replaced by $N=A I_{E}^{\omega}\left(E / L^{\phi}\right)^{1-\omega}$, and the coefficient $\theta$ in (36) would be equal to $-\phi(1-\omega)$.

Suppose also that now the number of uneducated individuals seeking to acquire skills depends positively on the wage paid to educated labor. ${ }^{24}$ Implicitly, therefore, the pay-off to remaining uneducated is zero (or, more generally, constant). In the present setting, with continuous clearing of the labor market, this wage is equal to the marginal product of educated labor, which from (1) is given by $\beta G^{\alpha} E^{\beta-1} K_{P}^{1-\alpha-\beta} \cdot{ }^{25}$ Thus,

$$
L=\Gamma\left[\beta\left(\frac{G}{K_{P}}\right)^{\alpha}\left(\frac{K_{P}}{E}\right)^{1-\beta}\right]
$$

\footnotetext{
${ }^{24}$ In principle, of course, it is the discounted present value of all future wages that should affect schooling decisions. However, this would complicate quite significantly the model and make the derivation of explicitly analytical solutions very difficult. Despite its relatively ad hoc nature, the specification chosen here is sufficient to illustrate the impact of congestion in education on the optimal share of spending on infrastructure.

${ }^{25}$ Given the Cobb-Douglas production technology, results similar to those derived below would obtain if the supply of individuals seeking an education were to depend on average income per educated worker, $Y / E$.
} 
where, in general, $\Gamma^{\prime}>0$ and $\Gamma^{\prime \prime}<0$. The raw labor supply decision (or, more precisely, the supply of raw labor seeking to acquire skills through public schools) is thus assumed to be separable from consumption decisions. ${ }^{26}$ Taking a linear approximation to $\Gamma$, and noting that $G / K_{P}=v \tau$, yields

$$
L=\beta \Gamma^{\prime}(\tau v)^{\alpha} e^{-(1-\beta)} .
$$

Substituting (38) in (36) yields

$$
\frac{\dot{E}}{E}=A\left[\beta \Gamma^{\prime}(\tau v)^{\alpha}\right]^{-\theta}\left[\left(\frac{I_{E}}{K_{P}}\right)\left(\frac{K_{P}}{E}\right)\right]^{\omega} e^{\theta(1-\beta)},
$$

which, using (11), can be rearranged to give

$$
\frac{\dot{E}}{E}=\frac{A[\tau(1-v)]^{\omega}}{\left[\beta \Gamma^{\prime}(\tau v)^{\alpha}\right]^{\theta}} e^{-[\omega-\theta(1-\beta)]} .
$$

Equations (12), (13), and (39) represent now the dynamic system driving the economy. Stability of the BGE and the transitional dynamics depend on the sign of $\omega-\theta(1-\beta)$, which affects the sign of $a_{22}$ in the Jacobian matrix of the dynamic system (24):

$$
a_{22}=-[\omega-\theta(1-\beta)] \frac{A[(1-v) \tau]^{\omega}}{\left[\beta \Gamma^{\prime}(v \tau)^{\alpha}\right]^{\theta}} \tilde{e}^{-[\omega-\theta(1-\beta)]}-\beta(\tau v)^{\alpha} \tilde{e}^{\beta} .
$$

If $\theta<\omega /(1-\beta)$, then $a_{22}<0$, and the condition for saddlepath stability is the same as given before. Given the definition of $\theta$, this condition implies that $\phi(1-\beta)<1$, which is always satisfied.

Given (39), equation (23) is now replaced by

$$
\gamma=\frac{A[(1-v) \tau]^{\omega}}{\left[\beta \Gamma^{\prime}(v \tau)^{\alpha}\right]^{\theta}} \tilde{e}^{-[\omega-\theta(1-\beta)]}, \quad \omega-\theta(1-\beta)>0,
$$

\footnotetext{
${ }^{26}$ More formally, raw labor supply could be assumed to enter separately in the instantaneous utility function, as for instance in Greiner (1999) or Palivos, Yip, and Zhang (2003), and solved for as part of the household's optimization problem. Given that this does not add much insight to the issue at hand, I restrict the discussion to specification (37).
} 
from which it can be established, given that (31) continues to hold, that

$$
v^{*}=\frac{\alpha(\omega-\theta)}{\alpha(\omega-\theta)+\omega \beta}=\frac{\alpha(1-\phi)}{\alpha(1-\phi)+\beta} .
$$

This formula is simply (32) if $\phi=0$. It implies that the higher the degree of congestion in education, the lower the optimal share of government spending on infrastructure services $\left(d v^{*} / d \phi<0\right)$. The reason is as follows. An increase in $v$, by raising the marginal product of educated labor, brings more students into public schools. Increased congestion tends to lower the supply of educated labor and thus the educated labor-capital ratio, which further increases the supply of raw labor (as a result of decreasing marginal returns to educated labor in production). The optimal policy, in response to higher congestion effects, is to increase spending on education (or, equivalently, reduce spending on infrastructure services), in order to offset this adverse effect on growth. With full or "proportional" congestion, that is, with $\phi=1$, the optimal share of spending on infrastructure is zero. For instance, with $\alpha=0.15, \beta=0.45$ (as in Agénor (2005b), for instance) the optimal share of spending on infrastructure is 25 percent of tax revenues with $\phi=0$, but only 14 percent with $\phi=0.5$.

These results continue to hold with independent shares and lump-sum transfers; as shown in Appendix B, the ratio of optimal shares is then given by, instead of (34),

$$
\frac{v^{*}}{v_{E}^{*}}=\frac{\alpha(1-\phi)}{\beta[1-\phi(1-\beta)]},
$$

which is equal to (34), that is, $\alpha / \beta$, if $\phi=0$. It can also be verified from this result that $d\left(v^{*} / v_{E}^{*}\right) / d \phi<0$.

As one would expect, both results depend crucially on the way the inflow of raw labor into public schools is modeled. Suppose, for instance, that the smaller the average quantity of physical capital that educated individuals have access to, the lower the incentive to acquire skills. Unlike the specification in (38), the supply of individuals seeking an education would be positively 
related to the ratio of educated labor to physical capital, $e$, perhaps because these individuals value the fact that the use of machines increases learning opportunities (as in Kosempel (2004)) and improves their productivity. This assumption can be captured in a simple (albeit ad hoc) manner by setting $L=e^{\kappa}$, with $\kappa>0$. As a result, and using (36), equation (39) is replaced by

$$
\frac{\dot{E}}{E}=A[(1-v) \tau]^{\omega} e^{-(\omega+\kappa \theta)} .
$$

Following the same reasoning as before, it can now be shown that

$$
v^{*}=\frac{\alpha(1+\kappa \phi)}{\alpha(1+\kappa \phi)+\beta} .
$$

This result is identical to (32) if either $\kappa=0$ or $\phi=0$. But now an increase in congestion costs raises the optimal share of spending on infrastructure services $\left(d v^{*} / d \phi>0\right)$. The reason why the adverse effect of a rise in $\phi$ on the steady-state growth rate can be mitigated by a higher $v$ is because an increase in $v$ lowers the (steady-state) educated labor-capital ratio, as established earlier, it now reduces the number of individuals seeking to acquire skills. The adverse effect of a greater degree of congestion in public schools on growth can therefore be offset by spending less on education and more on infrastructure.

\section{Concluding Remarks}

This paper studied the determination of the optimal allocation of public resources between infrastructure and education services. The analysis was based on an endogenous growth model in which raw labor must be educated to become productive and government spending is financed by a tax on installed capital. Unlike Lucas-type models, where private agents decide how much to invest in the acquisition of skills, education is mandatory, and the schooling technology involves government provision of education services. The balanced growth equilibrium is derived, and the transitional dynamics 
associated with an increase in the share of public spending on infrastructure services are characterized. Long-run growth is shown to be driven by taxfinanced public spending on education and infrastructure services. Besides the growth effect, the allocation of public expenditure affects the equilibrium path along which the economy converges to the balanced growth equilibrium path. The growth-maximizing share is shown to depend on the parameters characterizing the production technology.

The model is then extended to account for independent spending shares and lump-sum transfers, and congestion costs in education. The growthmaximizing share of public spending on infrastructure is shown to depend also on the education technology. Depending on what determines the supply of raw labor, the growth-maximizing share of government spending on infrastructure services was shown to depend either positively or negatively on the degree of congestion in education. In particular, even if the number of pupils has only negative effects on the rate of human capital accumulation, this does not imply that spending on education (infrastructure) should be reduced (increased) in response to an increase in the degree of congestion in schooling; on the contrary, if the decision to acquire skills is a function of the current wage (viewed perhaps as a proxy for future wages), the optimal response is a reduction in the share of spending on infrastructure.

The model developed in this paper can be extended in a variety of directions. One extension would be to account for private education (and subsidies to private schools), in addition to public education. This would allow an analysis of the growth and distributional effects of the two regimes, as in Zhang (1996), Glomm and Ravikumar (1992, 2003), and Glomm and Kaganovich (2003), in the presence of trade-offs between public education and infrastructure spending. A second extension would be to model congestion effects associated with public infrastructure and the stock of private capital. This would change the growth-maximizing rule (as well as the optimal rate of subsidies to private investment, for instance), which would then 
depend on the relative magnitude of congestion effects. A third extension would be to consider other forms of distortionary taxation, such as taxes on consumption, wages, or capital income, as for instance in Glomm and Ravikumar (1998), Turnovsky (2000, 2004) and Rivas (2003). With endogenous supply of (raw) labor, a tax on wages would also affect private decisions between labor and leisure, and the rate of growth. Blankenau and Simpson's (2004) analysis illustrates the importance of considering alternative methods of financing when evaluating the growth effects of increased spending on public education. A tax on the returns from private capital would affect decisions between consumption and investment, but both taxes are likely to have ambiguous effects on growth, because their adverse effect on private investment and labor supply may be offset by an increase in the stock of public capital.

Finally, it would be important to account for the fact that the provision of public services is related to the stock of capital, not the flow of spending. In a companion paper (see Agénor $((2005 b))$, I consider the case where public capital in infrastructure enters the production function of the economy. This is in line with Futagami, Morita, and Shibata (1993), and Fisher and Turnovsky (1998), who extended Barro's (1990) "flow" model. However, the resulting model is highly nonlinear and its transitional dynamics can be analyzed only through numerical methods. 


\section{References}

Agénor, Pierre-Richard, "Fiscal Policy and Endogenous Growth with Public Infrastructure," Working Paper No. 59, Centre for Growth and Business Cycle Research, University of Manchester (September 2005a).

-, "Schooling and Public Capital in a Model of Endogenous Growth," Working Paper No. 61, Centre for Growth and Business Cycle Research, University of Manchester (September 2005b).

- "Health and Infrastructure in Models of Endogenous Growth," Working Paper No. 62, Centre for Growth and Business Cycle Research, University of Manchester (September 2005c).

Baier, Scott L., and Gerhard Glomm, "Long-run Growth and Welfare Effects of Public Policies with Distortionary Taxation," Journal of Economic Dynamics and Control, 25 (December 2001), 1007-42.

Barro, Robert J., "Government Spending in a Simple Model of Endogenous Growth," Journal of Political Economy, 98 (October 1990), s103-s25.

Beauchemin, Kenneth R., "Growth or Stagnation? The Role of Public Education," Journal of Development Economics, 64 (April 2001), 389-416.

Blankenau, William F., and Nicole B. Simpson, "Public Education Expenditures and Growth," Journal of Development Economics, 73 (April 2004), 583-605.

Chang, Wen-Ya, "Government Spending, Endogenous Labor, and Capital Accumulation," Journal of Economic Dynamics and Control, 23 (August 1999), 1225-42.

Creedy, John, and Norman Gemmell, "Publicly Financed Education in an Endogenous Growth Model," Working Paper No. 02/24, New Zealand Treasury (December 2002).

Eicher, Theo, and Stephen J. Turnovsky, "Scale, Congestion, and Growth," Economica, 67 (August 2000), 325-46.

Fiaschi, David, "Growth and Inequality in an Endogenous Fiscal Policy Model with Taxes on Labor and Capital," European Journal of Political Economy, 15 (November 1999), 727-46.

Fisher, Walter H., and Christian Keuschnigg, "Public Policy for Efficient Education," Metroeconomica, 53 (November 2002), 361-90.

Fisher, Walter H., and Stephen Turnovsky, "Public Investment, Congestion, and Private Capital Accumulation," Economic Journal, 108 (March 1998), 399-413. 
Futagami, Koichi, Yuichi Morita, and Akihisa Shibata, "Dynamic Analysis of an Endogenous Growth Model with Public Capital," in Endogenous Growth, ed. by Torben M. Andersen and Karl O. Moene, Basil Blackwell (Oxford: 1993).

Glomm, Gerhard, and Michael Kaganovich, "Distributional Effects of Public Education in an Economy with Public Pensions," International Economic Review, 44 (August 2003), 917-38.

Glomm, Gerhard, and B. Ravikumar, "Public versus Private Investment in Human Capital: Endogenous Growth and Income Distribution," Journal of Political Economy, 100 (August 1992), 818-34.

_ - "Productive Govenment Expenditures and Long-Run Growth," Journal of Economic Dynamics and Control, 21 (January 1997), 183-204.

, "Flat-Rate Taxes, Government Spending on Education and Growth," Review of Economic Dynamics, 1 (January 1998), 306-25.

—, "Public Education and Income Inequality," European Journal of Political Economy, 19 (June 2003), 289-300.

Greiner, Alfred, "Fiscal Policy in an Endogenous Growth Model with Productive Government Spending," Metroeconomica, 50 (March 1999), 17493.

Heijdra, Ben J., and Lex Meijdam, "Public Investment and Intergenerational Distribution," Journal of Economic Dynamics and Control, 26 (May 2002), 707-35.

Kosempel, Stephen, "A Theory of Development and Long Run Growth," Journal of Development Economics, 75 (October 2004), 201-20.

Lucas, Robert E., "On the Mechanics of Economic Development," Journal of Monetary Economics, 22 (July 1988), 3-42.

$\mathrm{Ni}$, Shawn, and Xinghe Wang, "Human Capital and Income Taxation in an Endogenous Growth Model," Journal of Macroeconomics, 16 (June 1994), 493-507.

Palivos, Theodore, Chong K. Yip, and Junxi Zhang, "Transitional Dynamics and Indeterminacy of Equilibria in an Endogenous Growth Model with a Public Input," Review of Development Economics, 7 (February 2003), 86-98.

Park, Hyun, and Apostolis Philippopoulos, "Indeterminacy and Fiscal Policies in a Growing Economy," Journal of Economic Dynamics and Control, 28 (January 2004), 645-60.

Piras, Romano, "Government Spending Composition in an Endogenous Growth Model with Congestion," Metroeconomica, 52 (February 2001), 121- 
36.

Rioja, Felix K., and Gerhard Glomm, "Populist Budgets and Long-Run Growth," unpublished, Indiana University (April 2003).

Rivas, Luis A., "Income Taxes, Spending Composition and Long-Run Growth," European Economic Review, 47 (June 2003), 477-503.

Tamura, Robert, "Teachers, Growth, and Convergence," Journal of Political Economy, 109 (October 2001), 1021-59.

Tsoukis, Chris, and Nigel J. Miller, "Public Services and Endogenous Growth," Journal of Policy Modeling, 25 (April 2003), 297-307.

Turnovsky, Stephen, "Fiscal Policy, Adjustment Costs, and Endogenous Growth," Oxford

Economic Papers, 48 (July 1996), 361-81.

—- "Fiscal Policy, Elastic Labor Supply, and Endogenous Growth," Journal of Monetary Economics, 45 (February 2000), 185-210.

-, "The Transitional Dynamics of Fiscal Policy: Long-Run Capital Accumulation and Growth," Journal of Money, Credit, and Banking, 36 (October 2004), 883-910.

Turnovsky, Stephen J., and Walter H. Fisher, "Composition of Government Expenditure and its Consequences for Macroeconomic Performance," Journal of Economic Dynamics and Control, 19 (May 1995), 747-86.

UNESCO, Education for All Global Monitoring Report 2005: The Quality Imperative, UNESCO (Paris: 2005).

Van Zon, Adriaan, and Joan Muysken, "Health and Endogenous Growth," Journal of Health Economics, 20 (March 2001), 169-85.

Zagler, Martin, and Georg Durnecker, "Fiscal Policy and Economic Growth," Journal of Economic Surveys, 17 (July 2003), 397-418.

Zhang, Jie, "Optimal Public Investment in Education and Endogenous Growth," Scandinavian Journal of Economics, 98 (September 1996), 387-404. 


\section{Appendix A \\ Proportional Tax on Output}

With a proportional tax on output, the household's budget constraint (equation (2)) becomes

$$
C+\dot{K}_{P}=(1-\tau) Y
$$

and optimization leads to, instead of (6)),

$$
\frac{\dot{C}}{C}=(1-\alpha-\beta)(1-\tau)\left(\frac{G}{K_{P}}\right)^{\alpha}\left(\frac{E}{K_{P}}\right)^{\beta}-\rho .
$$

The government budget, equation (10), becomes $I_{E}+G=\tau Y$, and

$$
G=v \tau Y=v \tau\left(\frac{G}{K_{P}}\right)^{\alpha}\left(\frac{E}{K_{P}}\right)^{\beta} K_{P}, \quad I_{E}=(1-v) \tau\left(\frac{G}{K_{P}}\right)^{\alpha}\left(\frac{E}{K_{P}}\right)^{\beta} K_{P} .
$$

From (A1),

$$
\dot{K}_{P}=(1-\tau)\left(\frac{G}{K_{P}}\right)^{\alpha}\left(\frac{E}{K_{P}}\right)^{\beta} K_{P}-C,
$$

whereas, given (A3),

$$
\frac{G}{K_{P}}=\tau v\left(\frac{G}{K_{P}}\right)^{\alpha}\left(\frac{E}{K_{P}}\right)^{\beta}
$$

or equivalently,

$$
\frac{G}{K_{P}}=(\tau v)^{1 /(1-\alpha)}\left(\frac{E}{K_{P}}\right)^{\beta /(1-\alpha)}
$$

Thus,

$$
\frac{\dot{K}_{P}}{K_{P}}=(1-\tau)(\tau v)^{\alpha /(1-\alpha)}\left(\frac{E}{K_{P}}\right)^{\beta+[\alpha \beta /(1-\alpha)]}-\frac{C}{K_{P}},
$$

or, given that $\beta+[\alpha \beta /(1-\alpha)]=(\beta-\alpha \beta+\alpha \beta) /(1-\alpha)=\beta /(1-\alpha)$,

$$
\frac{\dot{K}_{P}}{K_{P}}=(1-\tau)(\tau v)^{\alpha /(1-\alpha)} e^{\beta /(1-\alpha)}-c .
$$

Similarly, using (A4), equation (A2) can be rewritten as

$$
\frac{\dot{C}}{C}=(1-\alpha-\beta)(1-\tau)(\tau v)^{\alpha /(1-\alpha)} e^{\beta /(1-\alpha)}-\rho .
$$


Using equation (9) with $\delta_{E}=0$ gives

$$
\frac{\dot{E}}{E}=B\left[\left(\frac{I_{E}}{K_{P}}\right)\left(\frac{K_{P}}{E}\right)\right]^{\omega \eta} .
$$

From (A3) and (A4),

$$
\frac{I_{E}}{K_{P}}=\tau(1-v)(\tau v)^{\alpha /(1-\alpha)}\left(\frac{E}{K_{P}}\right)^{\beta /(1-\alpha)} .
$$

Substituting this result in the previous equation gives

$$
\frac{\dot{E}}{E}=B\left[\tau(1-v)(\tau v)^{\alpha /(1-\alpha)}\right]^{\omega \eta}\left(\frac{E}{K_{P}}\right)^{[-1+\beta /(1-\alpha)] \omega \eta},
$$

so that

$$
\frac{\dot{E}}{E}=B\left[\tau(1-v)(\tau v)^{\alpha /(1-\alpha)}\right]^{\omega \eta} e^{-\chi}
$$

where $\chi \equiv(1-\alpha-\beta) \omega \eta /(1-\alpha)>0$.

Combining equations (A5), (A6), and (A7) yields

$$
\begin{gathered}
\frac{\dot{c}}{c}=-(\alpha+\beta)(1-\tau)(\tau v)^{\alpha /(1-\alpha)} e^{\beta /(1-\alpha)}-\rho+c, \\
\frac{\dot{e}}{e}=\Psi e^{-\chi}-(1-\tau)(\tau v)^{\alpha /(1-\alpha)} e^{\beta /(1-\alpha)}+c .
\end{gathered}
$$

where

$$
\Psi \equiv B\left[\tau(1-v)(\tau v)^{\alpha /(1-\alpha)}\right]^{\omega \eta} .
$$

The growth rate and the steady-state values of $c$ and $e$ are now determined by

$$
\begin{gathered}
\gamma=(1-\alpha-\beta)(1-\tau)(\tau v)^{\alpha /(1-\alpha)} \tilde{e}^{\beta /(1-\alpha)}-\rho, \\
\tilde{c}=\rho+(\alpha+\beta)(1-\tau)(\tau v)^{\alpha /(1-\alpha)} \tilde{e}^{\beta /(1-\alpha)}, \\
Q(\tilde{e} ; v)=0
\end{gathered}
$$

from which it can be shown again that $\partial \tilde{e} / \partial v<0$. The linearized dynamic system is now given as in (24), with coefficients $a_{i j}$ now given by

$$
\begin{gathered}
a_{11}=\tilde{c}, \quad a_{21}=\tilde{e}, \\
a_{12}=-\frac{\tilde{c} \beta}{1-\alpha}(\alpha+\beta)(1-\tau)(\tau v)^{\alpha /(1-\alpha)} \tilde{e}^{\beta /(1-\alpha)-1}<0,
\end{gathered}
$$




$$
a_{22}=-\chi \Psi \tilde{e}^{-\chi}-\frac{\beta(1-\tau)}{1-\alpha}(\tau v)^{\alpha /(1-\alpha)} \tilde{e}^{\beta /(1-\alpha)}<0,
$$

from which it can be established that $\Delta=a_{11} a_{22}-a_{12} a_{21}<0$. Thus, the BGE is also a saddlepoint. The phase diagram has the same qualitative features as those shown in Figure 1.

Using (A10), the impact of an increase in $v$ on the growth rate is now

$$
\frac{d \gamma}{d v}=(1-\alpha-\beta)(1-\tau)(\tau v)^{\alpha /(1-\alpha)} \tilde{e}^{\beta /(1-\alpha)}\left[\frac{\alpha}{1-\alpha} v^{-1}+\frac{\beta}{1-\alpha} \tilde{e}^{-1}\left(\frac{\partial \tilde{e}}{\partial v}\right)\right] .
$$

Thus, the growth-maximizing share is the solution of

$$
\frac{\alpha}{1-\alpha}+\frac{\beta}{1-\alpha}\left(\frac{v}{\tilde{e}}\right)\left(\frac{\partial \tilde{e}}{\partial v}\right)=0,
$$

that is, $v^{*}$ is such that

$$
\varepsilon_{\tilde{e} / v}=\frac{\alpha}{\beta},
$$

which is identical to (31).

Using (A7), the equivalent form of the growth rate is given by, instead of (23):

$$
\gamma=B\left[\tau(1-v)(\tau v)^{\alpha /(1-\alpha)}\right]^{\omega \eta} \tilde{e}^{-\chi}
$$

which implies that

$$
\frac{d \gamma}{d v}=\Psi\left[-\omega \eta(1-v)^{-1}+\frac{\alpha \omega \eta}{1-\alpha} v^{-1}-\chi \tilde{e}^{-1}\left(\frac{\partial \tilde{e}}{\partial v}\right)\right] .
$$

Thus, the growth-maximizing share is the solution of

$$
-\left(\frac{\omega \eta}{1-v}\right)+\frac{\alpha \omega \eta}{v(1-\alpha)}-\chi \tilde{e}^{-1}\left(\frac{\partial \tilde{e}}{\partial v}\right)=0,
$$

which gives, using the definition in (28),

$$
\frac{v^{*}}{1-v^{*}}=\frac{\alpha}{1-\alpha}+\frac{\chi}{\omega \eta} \varepsilon_{\tilde{e} / v}
$$

From the definition of $\chi, \chi / \omega \eta \equiv(1-\alpha-\beta) /(1-\alpha)$. Thus, using (A13), the above result becomes

$$
\frac{v^{*}}{1-v^{*}}=\frac{\alpha+(1-\alpha-\beta) \alpha / \beta}{1-\alpha} .
$$


This expression can be rewritten as

$$
\frac{v^{*}}{1-v^{*}}=\frac{\alpha(1-\alpha)}{\beta(1-\alpha)}=\frac{\alpha}{\beta}
$$

or equivalently

$$
v^{*}=\frac{\alpha}{\alpha+\beta}
$$

which is identical to (32).

Note also that if $\beta=0, v=1$, from (A6) the growth rate is

$$
\gamma=(1-\alpha)(1-\tau) \tau^{\alpha /(1-\alpha)}-\rho .
$$

Setting

$$
\frac{d \gamma}{d \tau}=(1-\alpha)\left[-\tau^{\alpha /(1-\alpha)}+\frac{\alpha(1-\tau)}{1-\alpha} \tau^{\alpha /(1-\alpha)-1}\right]=0,
$$

it can be established that the optimal value of $\tau$ is

$$
\tau^{*}=\alpha,
$$

as in Barro's (1990) model. However, in the general case where $\beta>0$, maximizing growth with respect to the tax rate is not equivalent to maximizing with respect to $v$. To find the optimal tax rate, note that solving for $d \gamma / d \tau=0$ in (A10) yields

$$
\frac{\alpha}{1-\alpha}+\frac{\beta \varepsilon_{\tilde{e} / v}}{1-\alpha}-\frac{\tau}{1-\tau}=0
$$

whereas from (A14), setting $d \gamma / d \tau=0$ yields

$$
\varepsilon_{\tilde{e} / v}=1 /(1-\alpha-\beta) .
$$

Substituting this result in the previous expression yields

$$
\tau^{*}=\alpha+\beta,
$$

which is independent of $v$. 


\section{Appendix B \\ Independent Shares and Lump-sum Transfers}

Suppose that the household receives lump-sum transfers, $T$, from the government. Its budget constraint, equation (2), becomes

$$
C+\dot{K}_{P}=Y-\tau K_{P}+T
$$

whereas the government budget constraint, equation (10), becomes

$$
I_{E}+G+T=\tau K_{P}
$$

Suppose again that $G=v \tau K_{P}$, but that the shares of spending on infrastructure and education are set independently of each other by the government, so that $I_{E}=v_{E} \tau K_{P}$, with $v, v_{E} \in(0,1)$. Thus, $G / I_{E}=v / v_{E}$, and changes in $v$ and $v_{E}$ can be analyzed separately.

By implication,

$$
T=\left(1-v-v_{E}\right) \tau K_{P}=q \tau K_{P}
$$

Substituting this result in (B1) yields

$$
\dot{K}_{P}=Y-C-(1-q) \tau K_{P},
$$

where $1-q \equiv v+v_{E} \in(0,1)$. Thus, the case considered in the text corresponds to $q=0$ and $v_{E}=1-v$.

Assuming that transfers are taken as given by the household when solving its optimization problem, the dynamics of consumption are given by, instead of $(6)$,

$$
\frac{\dot{C}}{C}=(1-\alpha-\beta)\left(\frac{G}{K_{P}}\right)^{\alpha}\left(\frac{E}{K_{P}}\right)^{\beta}-(1-q) \tau-\rho .
$$

Equations (12), (13), and (15) become, with $\delta_{E}=0$ for simplicity,

$$
\begin{gathered}
\frac{\dot{K}_{P}}{K_{P}}=(\tau v)^{\alpha} e^{\beta}-(1-q) \tau-c, \\
\frac{\dot{C}}{C}=(1-\alpha-\beta)(\tau v)^{\alpha} e^{\beta}-(1-q) \tau-\rho, \\
\frac{\dot{E}}{E}=B\left(\tau v_{E}\right)^{\omega \eta} e^{-\omega \eta},
\end{gathered}
$$


which can be combined to give, instead of (16) and (17),

$$
\begin{gathered}
\frac{\dot{c}}{c}=-(\alpha+\beta)(\tau v)^{\alpha} e^{\beta}-\rho+c, \\
\frac{\dot{e}}{e}=B\left(\tau v_{E}\right)^{\omega \eta} e^{-\omega \eta}-(\tau v)^{\alpha} e^{\beta}+(1-q) \tau+c,
\end{gathered}
$$

The BGE is again a saddlepoint and, from the implicit function corresponding to $(20), Q\left(\tilde{e} ; v, v_{E}\right)=0$, it can be shown that the uniqueness condition is $\rho+(1-q) \tau>0$, which always holds. This condition is similar to the one obtained earlier with $\delta_{E}=0$ (that is, $\rho+\tau>0$ ). It can also be established, using the implicit function theorem, that $\partial \tilde{e} / \partial v$ is ambiguous in sign, despite the fact that $v$ has no effect on the accumulation of educated labor (as implied by (B7)). The reason is that a rise in $v$ has two offsetting effects on the rate of accumulation of private capital and consumption. On the one hand, it tends to raise them, because of the productivity and output effects. On the other, it tends to reduce them, because it reduces transfers. These two effects can be seen directly in (B5) and (B6), given that $q$ depends on $v$. If the initial tax rate is small enough, the former will dominate the latter, and the net effect will be an increase in the private capital stock and consumption, so that $\partial \tilde{e} / \partial v<0$, as before. Using again the implicit function theorem, it can be shown that $\partial \tilde{e} / \partial v_{E}>0$.

From (B6), the growth-maximizing value of $v$ is now given by

$$
\frac{d \gamma}{d v}=(1-\alpha-\beta)(\tau v)^{\alpha} \tilde{e}^{\beta}\left[\alpha v^{-1}+\beta \tilde{e}^{-1}\left(\frac{\partial \tilde{e}}{\partial v}\right)\right]-\tau=0 .
$$

Noting that $\alpha v^{-1}+\beta \tilde{e}^{-1}(d \tilde{e} / d v)=v^{-1}\left(\alpha-\beta \varepsilon_{\tilde{e} / v}\right)$, this expression can be rewritten as

$$
\frac{d \gamma}{d v}=(1-\alpha-\beta)(\tau v)^{\alpha-1} \tilde{e}^{\beta}\left(\alpha-\beta \varepsilon_{\tilde{e} / v}\right)=1,
$$

which yields

$$
v^{*}=\min \left\{\tau^{-1}\left[\frac{(1-\alpha-\beta)\left(\alpha-\beta \varepsilon_{\tilde{e} / v}\right)}{\tilde{e}^{-\beta}}\right]^{1 /(1-\alpha)}, 1\right\} .
$$

This expression shows that the higher $\tau$ is, the lower $v^{*}$ will be. The reason is that the effect of the "transfer" rate on capital accumulation and 
consumption growth is proportional to $\tau$. A higher $v$ means a lower $q$, which tends to reduce $\dot{K}_{P} / K_{P}$ and $\dot{C} / C$ if $\tau>0$. The higher $\tau$ is, the greater the magnitude of this effect.

Note that, when $\beta=0$, this expression becomes

$$
v^{*}=\min \left\{\tau^{-1}[\alpha(1-\alpha)]^{1 /(1-\alpha)}, 1\right\},
$$

and that from (1), $\tilde{y}=\tilde{Y} / \tilde{K}_{P}=(\tau v)^{\alpha} \tilde{e}^{\beta}$, which implies that (B10) can be rewritten as

$$
(1-\alpha-\beta) \frac{\tilde{y}}{\tau v^{*}}\left(\alpha-\beta \varepsilon_{\tilde{e} / v}\right)=1 .
$$

Given that $v^{*}=G^{*} / \tau \tilde{K}_{P}$, the above expression is equivalent to, in terms of the ratio of the optimal spending level to output,

$$
v^{*} / \tilde{y}=G^{*} / \tilde{Y}=(1-\alpha-\beta)\left(\alpha-\beta \varepsilon_{\tilde{e} / v}\right) .
$$

From (B6), the optimal share of spending on education is given by

$$
\frac{d \gamma}{d v_{E}}=\beta(1-\alpha-\beta)(\tau v)^{\alpha} \tilde{e}^{\beta-1}\left(\frac{\partial \tilde{e}}{\partial v_{E}}\right)-\tau=0,
$$

which yields

$$
\frac{d \gamma}{d v_{E}}=\beta(1-\alpha-\beta)(\tau v)^{\alpha-1} \tilde{e}^{\beta}\left(\frac{v}{v_{E}}\right) \varepsilon_{\tilde{e} / v_{E}}=1
$$

and

$$
v_{E}^{*}=\min \left\{\frac{\beta(1-\alpha-\beta) v \varepsilon_{\tilde{e} / v_{E}}}{(\tau v)^{1-\alpha} \tilde{e}^{-\beta}}, 1\right\}
$$

with $v_{E}^{*}=0$ if $\beta=0$. With an interior solution, $v_{E}^{*}$ is a concave function of $v$, given that it depends on $v^{\alpha}$. It is also negatively related to $\tau$.

Alternatively, using (B7),

$$
\frac{d \gamma}{d v_{E}}=\omega \eta A\left(\tau v_{E}\right)^{\omega \eta} \tilde{e}^{-\omega \eta}\left[v_{E}^{-1}-\tilde{e}^{-1}\left(\frac{\partial \tilde{e}}{\partial v_{E}}\right)\right]
$$

which implies that $v_{E}^{-1}-\tilde{e}^{-1}\left(\partial \tilde{e} / \partial v_{E}\right)=0$, or that $\varepsilon_{\tilde{e} / v_{E}}=1$. Then $\varepsilon_{\tilde{e} / v}=$ $\varepsilon_{\tilde{e} / v_{E}} \varepsilon_{v_{E} / v}=\varepsilon_{v_{E} / v}$. Because the shares are independent, $\varepsilon_{v_{E} / v}=0$, so $\varepsilon_{\tilde{e} / v}=$ $0 .{ }^{27}$ Thus, assuming an interior solution, equations (B11) and (B13) become:

$$
v^{*}=\tau^{-1}\left[\frac{\alpha(1-\alpha-\beta)}{\tilde{e}^{-\beta}}\right]^{1 /(1-\alpha)},
$$

\footnotetext{
${ }^{27}$ Note that the result $\varepsilon_{\tilde{e} / v}=\partial \tilde{e} / \partial v=0$ follows directly from (B7), which implies $\gamma=A\left(\tau v_{E}\right)^{\omega \eta} \tilde{e}^{-\omega \eta}$, by setting $\partial \gamma / \partial v=0$.
} 


$$
v_{E}^{*}=\frac{\beta(1-\alpha-\beta) v}{(\tau v)^{1-\alpha} \tilde{e}^{-\beta}} .
$$

If both shares are set optimally at the same time, the second equation can be rewritten as

$$
\frac{v^{*}}{v_{E}^{*}}=\frac{\left(\tau v^{*}\right)^{1-\alpha} \tilde{e}^{-\beta}}{\beta(1-\alpha-\beta)},
$$

whereas the first implies that

$$
\left(\tau v^{*}\right)^{1-\alpha}=\frac{\alpha(1-\alpha-\beta)}{\tilde{e}^{-\beta}} .
$$

Combining these expressions yields $v^{*} / v_{E}^{*}=\alpha / \beta$, which is expression (34) in the text.

With congestion costs as in (35) and raw labor supply as in (37), equation (B7) is replaced by

$$
\frac{\dot{E}}{E}=A\left(\tau v_{E}\right)^{\omega \eta}\left[\beta L^{\prime}(\tau v)^{\alpha}\right]^{-\theta} e^{-[\omega \eta-\theta(1-\beta)]},
$$

from which it can be established that, instead of (B11),

$$
v^{*}=\min \left\{\tau^{-1}\left[\frac{\alpha(1-\alpha-\beta)(1-\eta-\theta)}{[1-\eta-\theta(1-\beta)] \tilde{e}^{-\beta}}\right]^{1 /(1-\alpha)}, 1\right\} \text {. }
$$

It can be verified that if $v^{*}$ is an interior solution, then $d v^{*} / d \phi<0$, for the reasons discussed in the text. The solution for $v_{E}^{*}$ is the same as before (equation (B15), so the composition of spending, given that both shares are chosen optimally, is given by

$$
\frac{v^{*}}{v_{E}^{*}}=\frac{\alpha(\omega \eta-\theta)}{\beta[\omega \eta-\theta(1-\beta)]}
$$

which is equal to (34), that is, $\alpha / \beta$, if $\theta=0$. It can be verified from this result that $d\left(v^{*} / v_{E}^{*}\right) / d \phi<0$. Setting $\eta=1$ in (B17), and noting that $\theta=\omega \phi$, yields (41).

Finally, from (B6), the growth-maximizing tax rate is determined by

$$
\frac{\partial \gamma}{\partial \tau}=\alpha(1-\alpha-\beta)(\tau v)^{\alpha} \tilde{e}^{\beta}\left[\alpha \tau^{-1}+\beta \tilde{e}^{-1}\left(\frac{\partial \tilde{e}}{\partial \tau}\right)\right]-(1-q)=0 .
$$


Noting that $\alpha \tau^{-1}+\beta \tilde{e}^{-1}(\partial \tilde{e} / \partial \tau)=\tau^{-1}\left(\alpha-\beta \varepsilon_{\tilde{e} / \tau}\right)$, this expression yields

$$
\alpha(1-\alpha-\beta)(\tau v)^{\alpha} \tilde{e}^{\beta} \tau^{-1}\left(\alpha-\beta \varepsilon_{\tilde{e} / \tau}\right)=1-q,
$$

which can be rewritten as

$$
\tau^{*}=\left[\frac{\alpha(1-\alpha-\beta) v^{\alpha}\left(\alpha-\beta \varepsilon_{\tilde{e} / \tau}\right)}{(1-q) \tilde{e}^{-\beta}}\right]^{1 /(1-\alpha)},
$$

From (B7), the growth-maximizing tax rate is also given by

$$
A(1-\eta)\left(\tau v_{E}\right)^{1-\eta} e^{-(1-\eta)}\left[\tau^{-1}-\tilde{e}^{-1}\left(\frac{\partial \tilde{e}}{\partial \tau}\right)\right]=0
$$

which implies that $\tau^{-1}-\tilde{e}^{-1}(\partial \tilde{e} / \partial \tau)=0$, or that $\varepsilon_{\tilde{e} / \tau}=-1$. (B18) then becomes

$$
\tau^{*}=\min \left\{\left[\frac{\alpha(1-\alpha-\beta) v^{\alpha}(\alpha+\beta)}{(1-q) \tilde{e}^{-\beta}}\right]^{1 /(1-\alpha)}, 1\right\} .
$$

Using equations (22) and (23) in the text, and following the same reasoning as above, it can be shown that the optimal tax rate is

$$
\tau^{*}=\min \left\{\left[\frac{(1-\alpha-\beta) v^{\alpha}(\alpha+\beta)}{\tilde{e}^{-\beta}}\right]^{1 /(1-\alpha)}, 1\right\} .
$$

which is identical to (B19) if $v_{E}=1-v$, because then $q=0$. Note that setting $\beta=0$ and $v=1$ in (B20) yields

$$
\tau^{*}=[\alpha(1-\alpha)]^{1 /(1-\alpha)} .
$$


Figure 1

The Steady-Growth Equilibrium

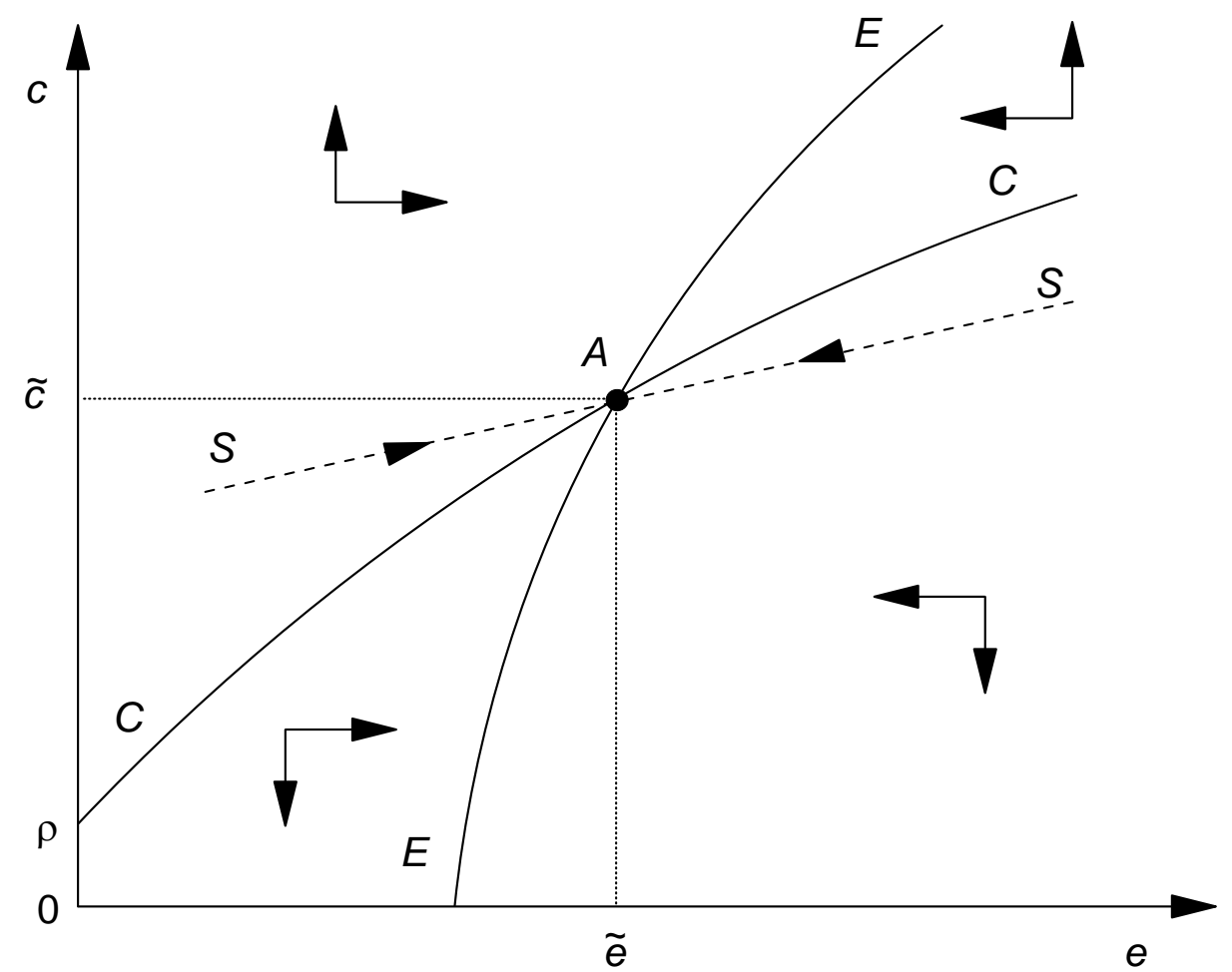


Figure 2

Permanent Increase in the Share of Public Spending on Infrastructure
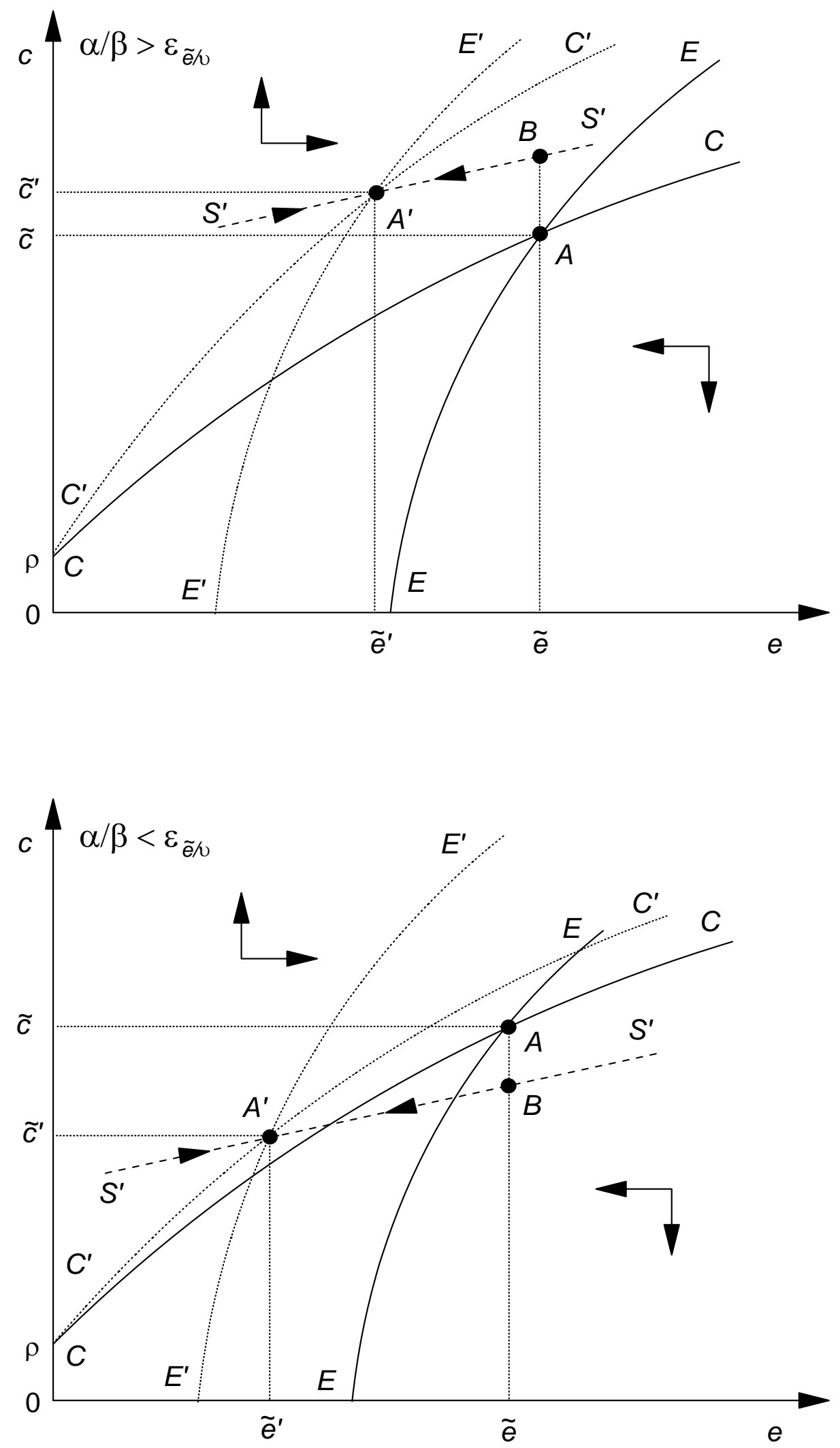
Figure 1

The Steady-Growth Equilibrium

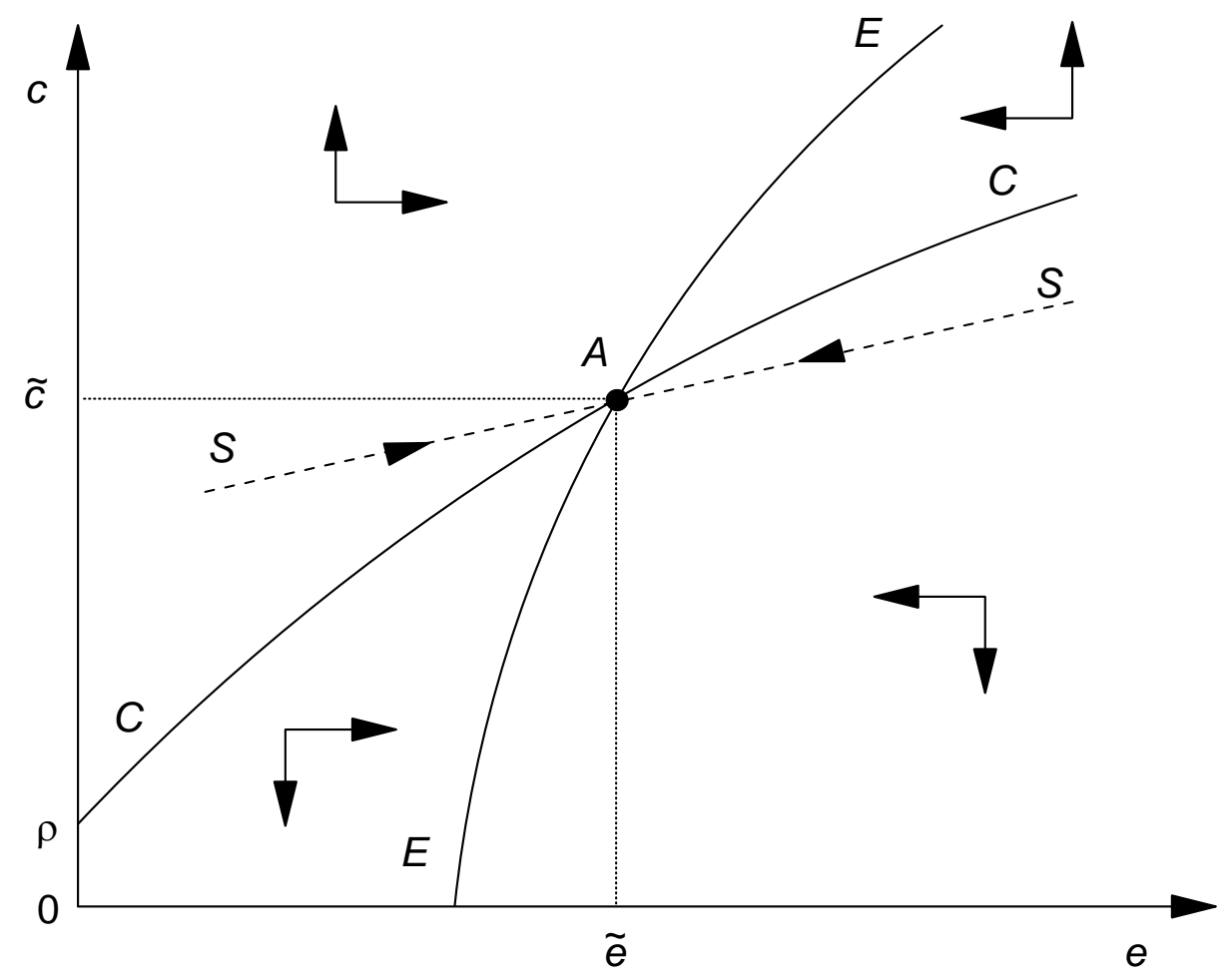


Figure 2

Permanent Increase in the Share of Public Spending on Infrastructure
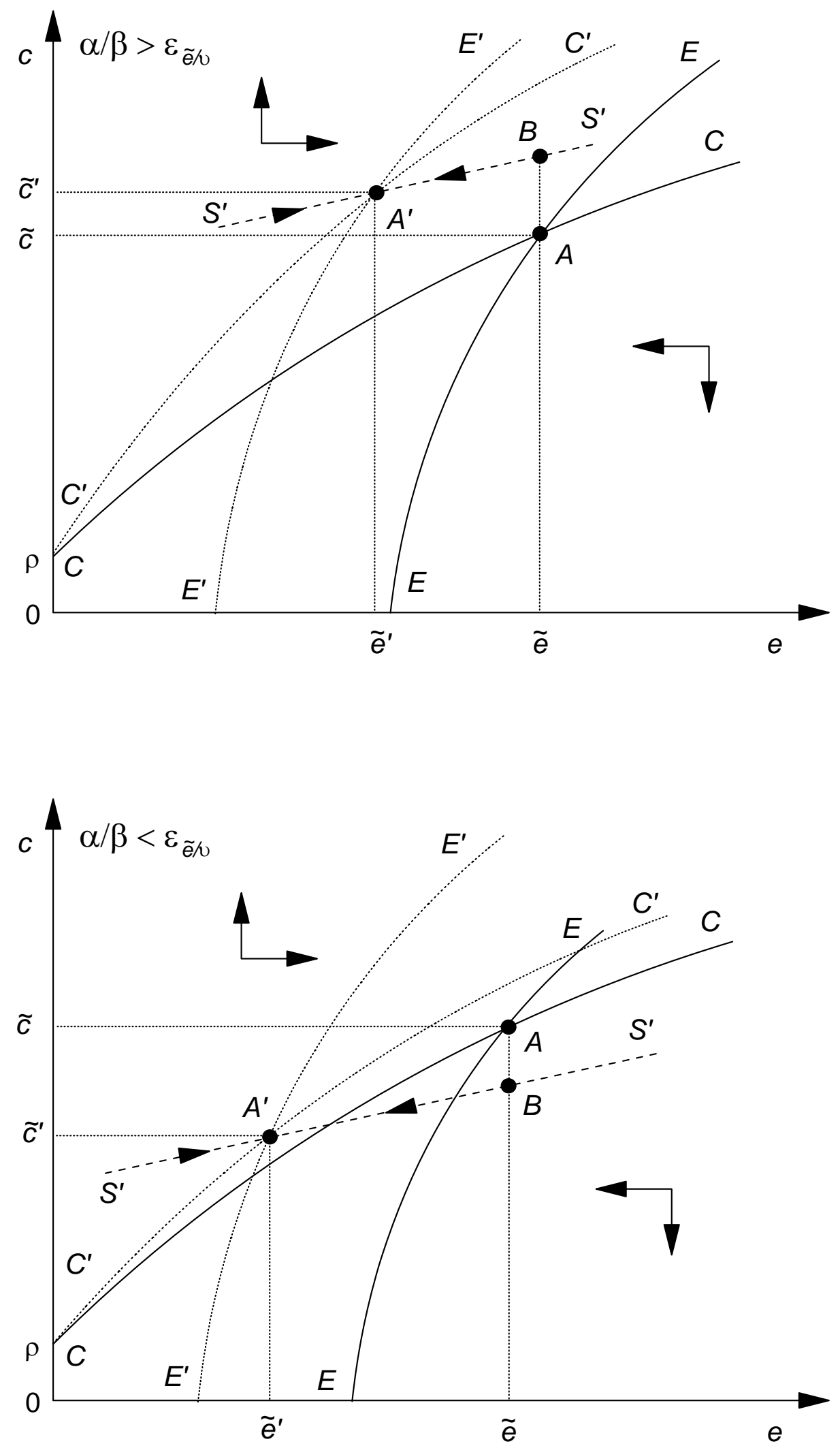